\title{
A Practical Catalyst-Free Synthesis of 6-Amino-4 Alkyl/Aryl-3- methyl-2,4-dihydropyrano[2,3-c]pyrazole-carbonitrile in Aqueous Medium
}

\author{
Manisha Bihani, Pranjal P. Bora, and Ghanashyam Bez \\ Department of Chemistry, North Eastern Hill University, Shillong 793022, India \\ Correspondence should be addressed to Ghanashyam Bez; ghanashyambez@yahoo.com
}

Received 25 June 2012; Accepted 30 July 2012

Academic Editor: John CG Zhao

Copyright (c) 2013 Manisha Bihani et al. This is an open access article distributed under the Creative Commons Attribution License, which permits unrestricted use, distribution, and reproduction in any medium, provided the original work is properly cited.

A completely green and improved method for the synthesis of 6-amino-4-aryl-3-methyl-2,4-dihydropyrano[2,3-c]pyrazolecarbonitriles by a four-component reaction of a mixture of ethyl acetoacetate, hydrazine hydrate, aldehyde, and malononitrile in boiling water is reported. Similar synthesis starting from aliphatic aldehydes was carried out in water: ethanol $(1: 1)$ at reflux temperature without using any catalyst.

\section{Introduction}

Multicomponent reactions (MCRs) [1-3] are getting a lot of applications in drug development efforts in recent years due to the fact that all the starting materials react in one-pot either simultaneously (so-called "tandem", "domino," or "cascade" reactions) or through a sequential-addition procedure to form a product, incorporating essentially all of the atoms of the reactants, and hence are highly atom economic. With the advent of combinatorial synthesis, multicomponent reactions (MCRs) strategy has been considered ideal to assemble large molecular libraries for screening bioactivity in medicinal chemistry. The MCRs have brought about a paradigm shift in designing organic reaction where the issues of atom economy and economy of steps are considered vital towards achieving greater molecular complexity. If such MCR reactions can be performed without use of catalyst in water medium, it can provide the perfect platform for green synthesis without percolating anything to destroy the environment.

In recent years, the synthesis of dihydropyrano[2,3c]pyrazole derivatives is getting tremendous attention among the synthetic chemists for their diverse bioactivity profiles, which include anticancer [8], anti-inflammatory [9], antimicrobial [10], and analgesic properties [11]. Nevertheless, the discovery of the inhibitory activity of the Chk1 kinase [12] by dihydropyrano[2,3-c]pyrazole derivatives from docking studies on a large electronic catalogue of compounds to its ATP-binding site and by assaying a relatively small number of prioritised compounds having dihydropyrano $[2,3-c]$ pyrazole moiety has prompted development of many efficient methods for their synthesis. Since the first synthesis of pyrano[2,3-c]pyrazoles by Junek and Aigner [13] from condensation of 3-methyl1-phenylpyrazolin-5-one and tetracyanoethylene in the presence of triethylamine, a host of catalytic methods involving bases, such as triethylamine $[5,13,14]$, piperidine [4], piperazine [7], and $N$-methylmorpholine [15] have been reported. In spite of being effective, the applicability of these methods is limited by the use of environmentally incompatible bases. Recently, Kanagaraj and Pitchumani [6] reported an efficient method to affect this synthesis with great ease by employing catalytic amount of per-6-amino$\beta$-cyclodextrin. Muramulla and Zhao [16], Gogoi and Zhao 
[17] have also successfully demonstrated the use of cinchonaderived organocatalysts for stereoselective synthesis of 6amino-4 alkyl/aryl-3-methyl-2,4-dihydropyrano [2,3-c]pyrazole-carbonitriles. Recently, Mecadon et al. [18] and Mecadon et al. [19] have disclosed the synthesis of 6-amino4 alkyl/aryl-3-methyl-2,4-dihydropyrano [2,3-c]pyrazolecarbonitriles in aqueous medium with environmentcompatible catalysts, such as L-proline and $\gamma$-alumina. But the use of hazardous organic solvents either in the isolation or in the purification process does not help the claims of the development of green methodologies for the said synthesis.

Although there are some catalytic methods $[4,18,19]$ for synthesis of 6-amino-4-alkyl/aryl-3-methyl-2,4-dihydropyrano[2,3-c]pyrazole-carbonitriles in aqueous medium, catalyst-free method for the said conversion is hardly explored. Vasuki et al. observed that catalyst-free method works only for benzaldehyde in the said synthesis [4]. Recently, Zou et al. [20] reported a catalyst-free method for synthesis of 6-amino-4-aryl-3-methyl-2,4dihydropyrano[2,3-c]pyrazole-carbonitrile in water at $50^{\circ} \mathrm{C}$ with or without ultrasound. Ironically, majority of the substrates (see Table 1 in Supplementary Materials available online at doi.org/10.1155/2013/920719)) without ultrasound never completed at $50^{\circ} \mathrm{C}$ in water in our hand, and reported yields were too high to achieve during the reported time in their reaction conditions. Moreover, complete isolation of the product by filtration of the reaction mixture is also erroneous, because most of the 6-amino-4-alkyl/aryl-3methyl-2,4-dihydropyrano[2,3-c]pyrazole-carbonitriles are sparingly soluble in water. Therefore, complete removal of water from the reaction mixture is a prerequisite when reaction is carried out in aqueous medium. In another interesting report [21], Reddy et al. accomplished the said synthesis under neat conditions without any catalyst at room temperature, but most of the reported yields (see Table 2 in Supporting Materials available online at http://dx.doi.org/10.1155/2013/920719) are far from being reproducible in the given time as per our experience with that method. In fact, the reactions proceeded very slowly after initial conversion and did not give complete conversion even after long reaction time. We observed that even upon grinding a neat mixture of ethyl acetoacetate, hydrazine hydrate, aldehyde, and malononitrile thoroughly took much longer time to achieve such yields [22].

With recent emphasis on development of green methodology, organic synthesis in water [23-29] is getting a lot of importance. Water is proven as a very good solvent [30-44] for many organic reactions and has its share of advantages, such as safety, cost, environmental concerns, unique redox stability, high heat capacity [45], and product isolation over conventional organic solvents. With the pioneering discovery by Breslow [46] on the role of water in rate acceleration of Diels-Elder reaction between nonpolar compounds in homogeneous organic solutions, various reports of "in-water" and "on-water" organic reactions have surfaced leading to generation of curiosity over the mechanistic insight of such reactions. As most of the organic compounds are insoluble in water, it facilitates easy purification through simple filtration technique. Additional advantages, such as high purity of the products to forgo chromatographic purification using hazardous organic solvents, high yields, short reaction time, and low-energy requirement, have contributed to enormous growth of organic reactions in water. Additionally, water is known to change its chemical and physical properties with change of temperature. Especially, ionic dissociation of water increases at $100^{\circ} \mathrm{C}(\mathrm{pKw} 12)$ due to generation of more hydronium and hydroxide ion as compared to that of water at room temperature $(\mathrm{pKw}$ 14) [47]. As a consequence, acid- and base-catalyzed reactions that cannot occur readily at ordinary temperatures could be promoted under elevated temperature. Given the above problems associated with catalyst and catalyst-free reactions, we assumed that synthesis of dihydropyrano[2,3c]pyrazole in boiling water may significantly increase overall synthetic efficiency of this highly useful building block. To that effect, we wish to report the completely green methodology for the synthesis of 6-amino-4-alkyl/aryl-3-methyl2,4-dihydropyrano[2,3-c]pyrazole-carbonitrile by refluxing a mixture of ethyl acetoacetate, hydrazine hydrate, aldehyde, and malononitrile in water without using any catalyst.

\section{Results and Discussion}

To start with, we a took mixture of hydrazine hydrate $(0.5 \mathrm{mmol})$ ethyl acetoacetate (1 equiv) in water and allowed to stir for $5 \mathrm{~min}$. To the mixture, $p$-nitrobenzaldehyde $(0.5 \mathrm{mmol})$ and malononitrile (1 equiv) were added and allowed to stir at room temperature. Interestingly, TLC monitoring of the reaction after $1 \mathrm{~h}$ revealed the formation of a polar product. Encouraged by that observation, we extended the reaction time and were pleased to find that the reaction completes in $5 \mathrm{~h}$ to give the desired product, which was confirmed by ${ }^{1} \mathrm{HNMR}$ and IR spectroscopy data. When the reaction temperature was raised to $50^{\circ} \mathrm{C}$, the reaction was found to complete within $3 \mathrm{~h}$. Since $p$-nitrobenzaldehyde has highly electrophilic aldehyde group to render high activity, we wanted to test the same reaction protocol for a relatively less electrophilic aldehyde, $m$, $p$-dimethoxybenzaldehyde, keeping the other parameters constant. Ironically, the reaction did not give the desired product to the slightest even after stirring for $10 \mathrm{~h}$. When the said reaction mixture was stirred at reflux for $6 \mathrm{~h}$, it led to completion of the reaction to give the desired product. When the reaction was tried for $p$-nitrobenzaldehyde at reflux temperature, the reaction was complete within $2 \mathrm{~h}$. All the starting materials were found to be consumed to form a single product that precipitates on the wall of the reaction vessel as the reaction progresses. After confirming the structure, we mixed the same set of reactants together and refluxed for $2 \mathrm{~h}$ to find that reaction gave many side products along with the desired product. This observation led us to assume that the order of addition of aldehyde is very important factor because it may react with all the remaining reactants to generate the Schiff base, (4-nitrobenzylidene)hydrazine and Knoevenagel condensation products. Especially the effect of the order of addition is more prominent in case of aliphatic aldehydes, albeit being less pronounced in 


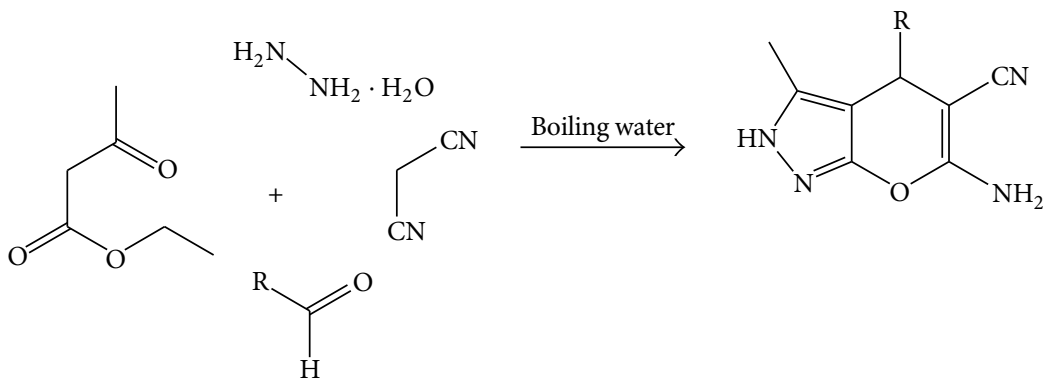

Scheme 1: Synthesis of dihydropyrano[2,3-c]pyrazole.

the cases of aromatic aldehydes. Therefore, we added the aldehyde (1 mmol) and malononitrile (1 equiv) later to a prestirred solution of hydrazine hydrate (1 equiv) and ethyl acetoacetate (1 equiv) mixture in water and refluxed for $2 \mathrm{~h}$. Here too, the reactants got converted to form only the desired product without any side product justifying our assumption regarding the order of addition of aldehyde.

Having standardized the process, we set out to generalize the application of this method to synthesize a series of dihydropyrano[2,3-c]pyrazoles from various aliphatic and aromatic aldehydes. In case of aromatic aldehydes, the nature of substituent on the phenyl rings did not have appreciable effect on overall yields of the product. Although the less nucleophilic aromatic aldehydes having substituents with $+\mathrm{M}$-effect have shown poor reactivity at room temperature, but they work extremely well at elevated temperature (Table 1). The reaction gave excellent yields for the electron deficient aldehydes even at room temperature (entry $1-5$, Table 1$)$. The position ( $o^{-}, \mathrm{m}^{-}$, and $\left.\mathrm{p}^{-}\right)$of the substituent on the phenyl ring did not show any noticable effect on either the reaction time or the yield. This led to the conclusion that it is the inductive (I) effect that affects the reaction rate, not the mesomeric (M) effect.

Although the synthesis of 6-amino-4 alkyl/aryl-3-methyl-2,4-di-hydropyrano[2,3-c] pyrazole-carbonitriles from aromatic aldehyde is generally reported, synthesis from aliphatic aldehyde is restricted to only one or two substrates by most of the literature methods. As most of the methods are base catalyzed, there might be possibility of formation of aldol products by self-condensation of aliphatic aldehydes carrying $\alpha$-hydrogen. When we tried to extrapolate our method to aliphatic aldehydes, it was observed that reaction yield for the reaction of butyraldehyde $(1 \mathrm{mmol})$ with hydrazine hydrate (1 equiv), ethyl acetoacetate ( 1 equiv), and malononitrile ( 1 equiv) in water $(5 \mathrm{~mL})$ was rather poor even after prolonged reflux. We assumed that the result may be due to poor solubility of aliphatic aldehydes in water. To clear our apprehension regarding the solubility, we added ethanol $(5 \mathrm{~mL})$ to a mixture of hydrazine hydrate $(1 \mathrm{mmol})$, ethyl acetoacetate (1 equiv), butyraldehyde (1 equiv) and malononitrile ( 1 equiv), in water $(5 \mathrm{~mL})$ and stirred at reflux and constantly monitored by TLC. The reaction was found to be complete after $10 \mathrm{~h}$ and gave very good yield (entry 1 , Table 2). When other aliphatic aldehydes (entries 1, 3-4) were reacted under similar reaction conditions, very good yields were observed. It was observed that the more electrophilic aldehydes (entries 5-6, Table 2) react faster than the other aldehydes having alkyl groups with + I-effect (entries 1-4, Table 2), and the addition of ethanol was not required to affect these transformations.

As for the mechanism, the 3-methyl-1H-pyrazol-5(4H)one 1 resulted from condensation of ethyl acetoacetate and hydrazine hydrate might have undergone tautomerisation to generate 3-methyl-1H-pyrazol-3-ol 2 and reacted with the Knoevenagel product 3 via Michael type addition reaction. The intermediate 4 , so generated, undergoes intramolecular cyclization to give the dihydropyrano[2,3-c]pyrazole derivative 5 (Scheme 2).

\section{Conclusion}

To conclude, we have reported a completely green and improved method for the synthesis of 6-amino-4 alkyl/aryl3-methyl-2,4-dihydropyrano[2,3-c] pyrazole-carbonitrile by refluxing a mixture of ethyl acetoacetate, hydrazine hydrate, aldehyde, and malononitrile in water without any catalyst. All the products were purified by recrystallization from ethanol, and hence, chromatographic purification and the use of hazardous organic solvents could be eliminated. For the first time, the synthesis of 6-amino-4 alkyl-3-methyl2,4-dihydropyrano[2,3-c]pyrazole-carbonitrile starting from aliphatic aldehydes has been generalized by taking six substrates. Given the operational simplicity, high yield, and environmental benign nature of this protocol, it can readily be applied to prepare large library of 6-amino-4 alkyl/aryl3-methyl-2,4-dihydropyrano[2,3-c]pyrazole-carbonitrile for further biological studies.

\section{Experimentals}

All the chemicals were purchased from Sigma-Aldrich Ltd. and were used without purification. IR spectra were recorded on a Perkin-Elmer Spectrum One FTIR spectrometer. ${ }^{1} \mathrm{H}$ and ${ }^{13} \mathrm{C}$ NMR spectra were recorded on a Bruker $(400 \mathrm{MHz})$ spectrometer using TMS as internal reference. ${ }^{13} \mathrm{C} \mathrm{NMR}$ spectra were recorded at $100 \mathrm{MHz}$ with $\left(\mathrm{CD}_{3}\right)_{2} \mathrm{SO}$ as solvents. Mass spectra were obtained from Waters ZQ 4000 mass spectrometer by the ESI method, while the elemental analyses of the complexes were performed on a Perkin-Elmer 2400 $\mathrm{CHN} / \mathrm{S}$ analyzer. TLC plates were visualized by UV or by 
TABLE 1: Synthesis of 6-amino-4-aryl-3-methyl-2,4-dihydropyrano[2,3-c]pyrazole-carbonitriles via Scheme $1^{\mathrm{a}}$.

\begin{tabular}{|c|c|c|c|c|c|}
\hline Entry & Aldehyde & Product $^{\mathrm{b}}$ & Time (h) & $\%$ Yield $^{\mathrm{c}}$ & m.p. $\left({ }^{\circ} \mathrm{C}\right)[\mathrm{Ref}]$ \\
\hline 1 & & $1 \mathrm{a}$ & 2 & 95 & $195[4]$ \\
\hline 2 & & $1 b$ & 2 & 90 & $191[4]$ \\
\hline 3 & & $\mathrm{NH}_{2}$ & 2 & 87 & $222-224[5]$ \\
\hline 4 & & $\mathrm{NH}_{2}$ & 4 & 80 & $175[4]$ \\
\hline 5 & & & 4 & 78 & $177[6]$ \\
\hline 6 & & $\mathrm{NH}_{2}$ & 4 & 76 & $169[4]$ \\
\hline 7 & & $\mathrm{H}_{2}$ & 5 & 80 & $174[4]$ \\
\hline 8 & & $\mathrm{NH}_{2}$ & 4 & 90 & $195[4]$ \\
\hline
\end{tabular}


TABLE 1: Continued.

Entry Aldehyde

Reaction conditions: Stoichiometric ratio of ethyl acetoacetate, hydrazine hydrate, aldehyde, and malononitrile were refluxed in water. ${ }^{\mathrm{b}}$ The products were purified by recrystallization from ethanol. ${ }^{c}$ Yield of the pure product.

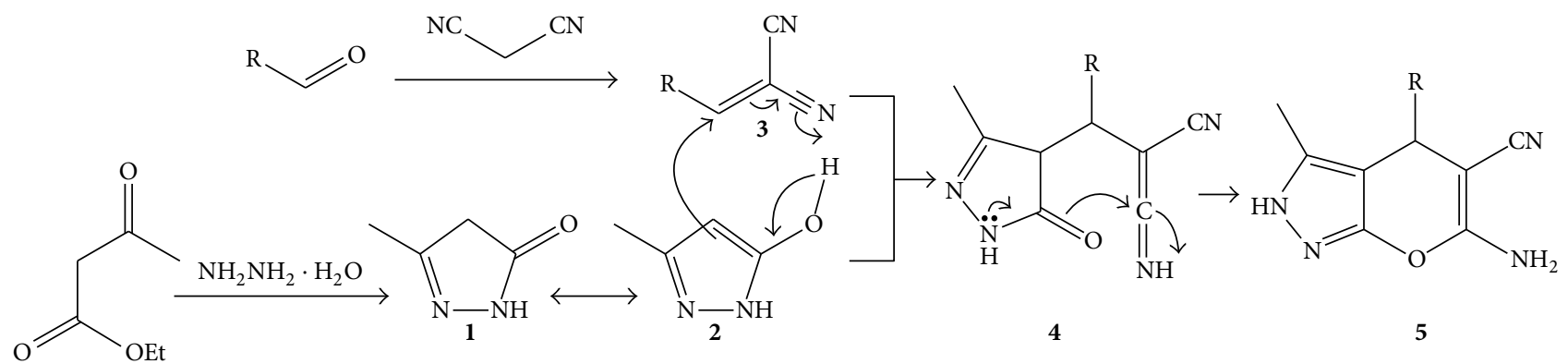

Scheme 2: Plausible mechanism.

immersion in anisaldehyde stain (by volume: 95\% ethanol, $3.5 \%$ sulfuric acid, $1 \%$ acetic acid, and 2.5\% anisaldehyde) followed by heating.

4.1. Typical Experimental Procedure. To a mixture of hydrazine hydrate ( $1 \mathrm{mmol}$ ) and ethylacetoacetate (1 equiv), $10 \mathrm{~mL}$ of distilled water (in case of aliphatic aldehydes, $5 \mathrm{~mL}$ of ethanol and of $5 \mathrm{~mL}$ water) was added and stirred for 5 minutes. Then, aldehyde (1 equiv) and malononitrile (1 equiv) were added to it and stirred with reflux for specified time. After completion, the reaction mixture was cooled, and water was removed in vacuo. The residue was dried and recrystallized from warm ethanol to afford the pure product.

\subsection{Spectral Data of New Compounds}

4.2.1. 6-Amino-4-(benzo [d][1,3]dioxol-5-yl)-3-methyl-2,4dihydropyrano [2,3-c]pyrazole-5-carbonitrile (1i). IR (KBr): 1043, 1248, 1401, 1493, 1600, 1646, 2190, 3184, $3370 \mathrm{~cm}^{-1}$; ${ }^{1} \mathrm{H}$ NMR (400 MHz, DMSO- $d_{6}$ ): $\delta 1.75(\mathrm{~s}, 3 \mathrm{H}), 4.46(\mathrm{~s}, 1 \mathrm{H})$, $5.91(\mathrm{~s}, 2 \mathrm{H}), 6.59(\mathrm{~m}, 2 \mathrm{H}), 6.76(\mathrm{~s}, 1 \mathrm{H}), 6.78(\mathrm{~s}, 1 \mathrm{H}), 12.03(\mathrm{~s}$, $1 \mathrm{H}) .{ }^{13} \mathrm{C}$ NMR $\left(100 \mathrm{MHz}, \mathrm{DMSO}-d_{6}\right): \delta 9.7,35.8,57.3,97.6$, $100.9,107.6,107.9,120.5,120.7,135.6,138.5,145.9,147.3$, 154.6, 160.7. MS $\left(\mathrm{ES}^{+}\right) m / z 297.0(\mathrm{M}+\mathrm{H})^{+}, 319.0(\mathrm{M}+\mathrm{Na})^{+}$. Elemental analysis for $\mathrm{C}_{15} \mathrm{H}_{12} \mathrm{~N}_{4} \mathrm{O}_{3}$ : calculated $\mathrm{C} 60.81, \mathrm{H}$ 4.08, N 18.91; observed C 60.76, H 4.04, N 18.95.
4.2.2. 6-Amino-4-hexyl-3-methyl-2,4-dihydropyrano[2,3-c] pyrazole-5-carbonitrile (2d). IR (KBr): 731, 1069, 1401, $1487,1606,1646,2190,2925,3131,3264 \mathrm{~cm}^{-1} ;{ }^{1} \mathrm{H} \mathrm{NMR}$ $\left(400 \mathrm{MHz}, \mathrm{DMSO}-d_{6}\right): \delta 0.764(\mathrm{t}, J=6.4 \mathrm{~Hz}, 3 \mathrm{H}), 0.90-1.14$ $(\mathrm{m}, 8 \mathrm{H}), 1.48-1.55(\mathrm{~m}, 2 \mathrm{H}), 2.08(\mathrm{~s}, 3 \mathrm{H}), 3.49(\mathrm{t}, J=4.4 \mathrm{~Hz}$, $2 \mathrm{H}), 6.68(\mathrm{~s}, 2 \mathrm{H}), 11.97(\mathrm{~s}, 1 \mathrm{H}) .{ }^{13} \mathrm{C} \mathrm{NMR}(100 \mathrm{MHz}$, DMSO- $\left.d_{6}\right): 10.1,13.9,21.9,23.7,28.7,29.5,31.2,34.8,55.1$, 96.7, 121.0, 134.8, 155.6, 161.8. MS $\left(\mathrm{ES}^{+}\right) \mathrm{m} / z 261.0(\mathrm{M}+$ $\mathrm{H})^{+}, 283.0(\mathrm{M}+\mathrm{Na})^{+}$. Elemental analysis for $\mathrm{C}_{14} \mathrm{H}_{20} \mathrm{~N}_{4} \mathrm{O}$ : calculated C 64.59, H 7.74, N 21.52; observed C 64.52, H 7.66, N 21.58.

4.2.3. 6-Amino-4-(2,2-dimethyl-1,3-dioxolan-4-yl)-3-methyl2,4-dihydropyrano[2,3-c]pyrazole-5-carbonitrile (2e). IR (KBr): 751, 857, 1076, 1401, 1593, 1646, 2196, 2866, 2985, $3104,3244 \mathrm{~cm}^{-1} ;{ }^{1} \mathrm{H}$ NMR (400 MHz, DMSO- $\left.d_{6}\right): \delta 1.16(\mathrm{~s}$, $3 \mathrm{H}), 1.25(\mathrm{~s}, 3 \mathrm{H}), 2.13(\mathrm{~s}, 3 \mathrm{H}), 3.50(\mathrm{~d}, J=2 \mathrm{~Hz}, 1 \mathrm{H}), 3.57$ $(\mathrm{t}, J=7.6 \mathrm{~Hz}, 1 \mathrm{H}), 3.83(\mathrm{t}, J=8 \mathrm{~Hz}, 1 \mathrm{H}),(\mathrm{q}, J=6 \mathrm{~Hz}, 1 \mathrm{H})$, $6.90(\mathrm{~s}, 2 \mathrm{H}), 12.04(\mathrm{~s}, 1 \mathrm{H}) .{ }^{13} \mathrm{C}$ NMR $\left(100 \mathrm{MHz}, \mathrm{DMSO}-d_{6}\right)$ : $10.4,25.1,25.9,33.9,50.9,65.9,80.1,95.3,108.4,121.4$, 136.1, 155.5, 163.1. MS $\left(\mathrm{ES}^{+}\right) \mathrm{m} / z 277.0(\mathrm{M}+\mathrm{H})^{+}, 299.0(\mathrm{M}$ $+\mathrm{Na})^{+}$. Elemental analysis for $\mathrm{C}_{13} \mathrm{H}_{16} \mathrm{~N}_{4} \mathrm{O}_{3}$ : calculated $\mathrm{C}$ 56.51, H 5.84, N 20.28; observed C 56.49, H 5.81.66, N 20.30.

4.2.4. Ethyl 6-Amino-5-cyano-3-methyl-2,4-dihydropyrano [2,3-c]pyrazole-4-carboxylate (2f). IR (KBr): 565, 665, 857, 
TABLE 2: Synthesis of 6-amino-4-alkyl-3-methyl-2,4-dihydropyrano[2,3-c]pyrazole-carbonitriles ${ }^{\mathrm{a}}$.

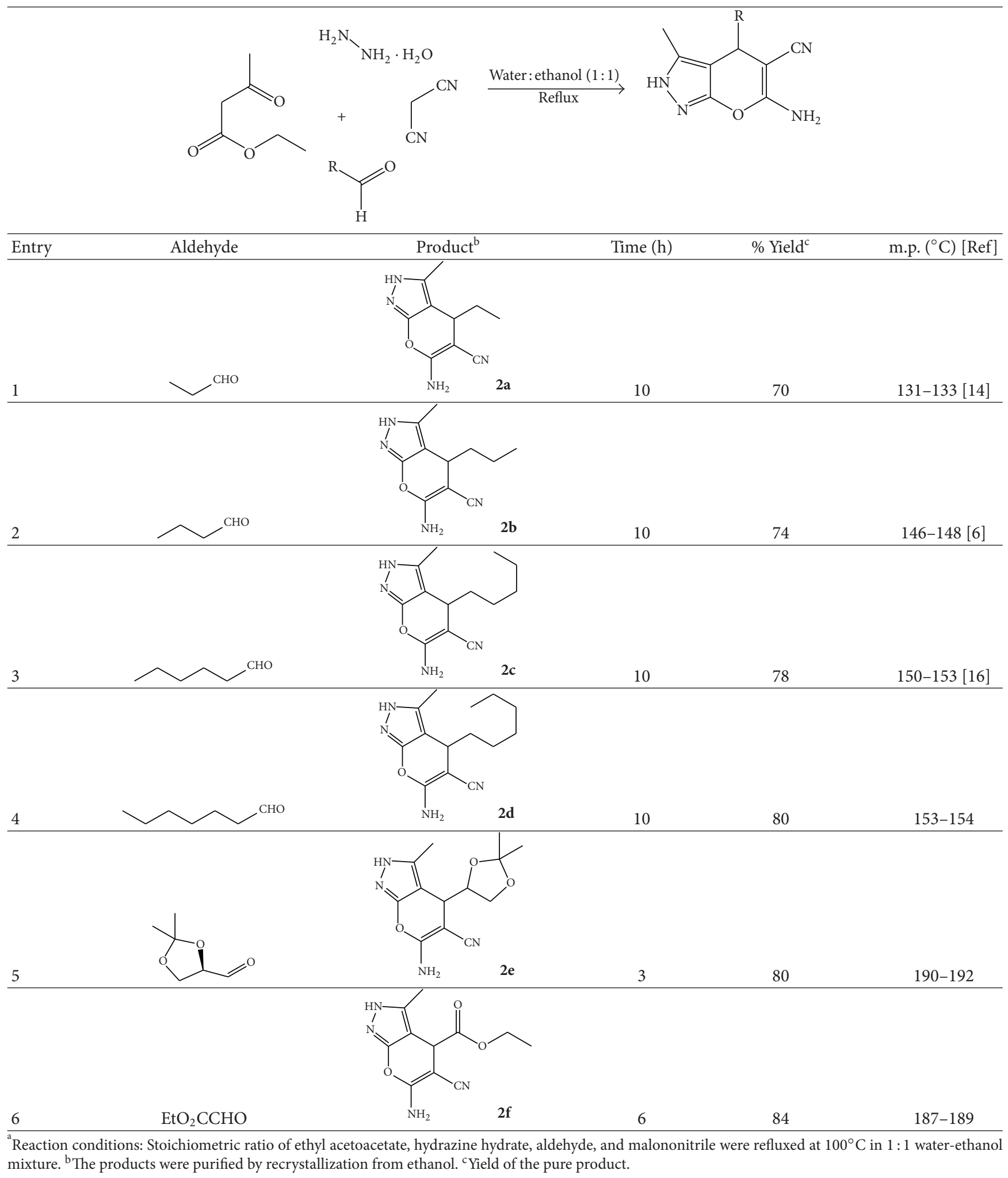


$1049,1175,1248,1533,1600,1732,2196,2614,2939$, $3409 \mathrm{~cm}^{-1} ;{ }^{1} \mathrm{H}$ NMR $\left(400 \mathrm{MHz}, \mathrm{DMSO}-d_{6}\right): \delta 1.17(\mathrm{t}, J=$ $7.2 \mathrm{~Hz}, 3 \mathrm{H}), 2.13(\mathrm{~s}, 3 \mathrm{H}), 4.10(\mathrm{q}, J=7.2 \mathrm{~Hz}, 2 \mathrm{H}), 4.31(\mathrm{~s}, 1 \mathrm{H})$, 7.09 (s, 2H), 12.27 (s, 1H). ${ }^{13} \mathrm{C}$ NMR (100 MHz, DMSO- $\left.d_{6}\right)$ : 9.8, 14.0, 36.5, 50.8, 61, 92.2, 120.3, 136.3, 154.8, 161.9, 171.5. MS $\left(\mathrm{ES}^{+}\right) \mathrm{m} / z 249.0(\mathrm{M}+\mathrm{H})^{+}, 271.0(\mathrm{M}+\mathrm{Na})^{+}$. Elemental analysis for $\mathrm{C}_{11} \mathrm{H}_{12} \mathrm{~N}_{4} \mathrm{O}_{3}$ : calculated $\mathrm{C} 53.22, \mathrm{H} 4.87, \mathrm{~N}$ 22.57; observed C 53.09, H 4.77, N 22.62.

\section{Acknowledgments}

Thanks are due to UGC, New Delhi ((Grant no. 31-54/2005 (SR)), CSIR, New Delhi (Grant no. 01(1992)/05/EMR-II) and DST, New Delhi (Grant no. SR/S1/OC-25/2007) for providing financial supports to carry out this work. The analytical services provided by SAIF, NEHU are highly appreciated.

\section{References}

[1] B. B. Touré and D. G. Hall, "Natural product synthesis using multicomponent reaction strategies," Chemical Reviews, vol. 109, no. 9, pp. 4439-4486, 2009.

[2] A. Dömling and I. Ugi, "Multicomponent reactions with isocyanides," Angewandte Chemie, vol. 39, no. 18, pp. 3169-3210, 2000 .

[3] C. O. Kappe, "Recent advances in the Biginelli dihydropyrimidine synthesis. New tricks from an old dog," Accounts of Chemical Research, vol. 33, no. 12, pp. 879-888, 2000.

[4] G. Vasuki and K. Kumaravel, "Rapid four-component reactions in water: synthesis of pyranopyrazoles," Tetrahedron Letters, vol. 49, no. 39, pp. 5636-5638, 2008.

[5] H. M. Al-Matar, K. D. Khalil, A. Y. Adam, and M. H. Elnagdi, "Green one pot solvent-free synthesis of pyrano[2,3-c]pyrazoles and pyrazolo[1,5-a]pyrimidines," Molecules, vol. 15, no. 9, pp. 6619-6629, 2010.

[6] K. Kanagaraj and K. Pitchumani, "Solvent-free multicomponent synthesis of pyranopyrazoles: per-6-amino- $\beta$-cyclodextrin as a remarkable catalyst and host," Tetrahedron Letters, vol. 51, no. 25, pp. 3312-3316, 2010.

[7] Y. Peng, G. Song, and R. Dou, "Surface cleaning under combined microwave and ultrasound irradiation: flash synthesis of $4 \mathrm{H}$-pyrano[2,3-c]pyrazoles in aqueous media," Green Chemistry, vol. 8, no. 6, pp. 573-575, 2006.

[8] J. L. Wang, D. Liu, Z. J. Zhang et al., "Structure-based discovery of an organic compound that binds Bcl-2 protein and induces apoptosis of tumor cells," Proceedings of the National Academy of Sciences of the United States of America, vol. 97, no. 13, pp. 7124-7129, 2000.

[9] M. E. A. Zaki, H. A. Soliman, O. A. Hiekal, and A. E. Rashad, "Pyrazolopyranopyrimidines as a class of anti-inflammatory agents," Zeitschrift für Naturforschung C, vol. 61, no. 1-2, pp. $1-5,2006$.

[10] E. S. H. El-Tamany, F. A. El-Shahed, and B. H. Mohamed, "Synthesis and biological activity of some pyrazole derivatives," Journal of the Serbian Chemical Society, vol. 64, no. 1, pp. 9-18, 1999.
[11] S. C. Kuo, L. J. Huang, and H. Nakamura, "Studies on heterocyclic compounds. 6. Synthesis and analgesic and antiinflammatory activities of 3,4-dimethylpyrano[2,3-c]pyrazol-6one derivatives," Journal of Medicinal Chemistry, vol. 27, no. 4, pp. 539-544, 1984.

[12] N. Foloppe, L. M. Fisher, R. Howes, A. Potter, A. G. S. Robertson, and A. E. Surgenor, "Identification of chemically diverse Chk1 inhibitors by receptor-based virtual screening," Bioorganic and Medicinal Chemistry, vol. 14, no. 14, pp. 4792-4802, 2006.

[13] H. Junek and H. Aigner, "Syntheses with nitriles. XXXV. Reactions of tetracyanoethylene with heterocycles," Chemische Berichte, vol. 106, no. 3, pp. 914-921, 1973.

[14] Y. M. Litvinov, A. A. Shestopalov, L. A. Rodinovskaya, and A. M. Shestopalov, "New convenient four-component synthesis of 6-amino-2,4-dihydropyrano[2,3-c] pyrazol-5carbonitriles and one-pot synthesis of $6^{\prime}$-aminospiro[(3H)indol-3, 4' pyrano[2,3-c]pyrazol]-(1H)-2-on-5' -carbonitriles," Journal of Combinatorial Chemistry, vol. 11, no. 5, pp. 914-919, 2009.

[15] F. Lehmann, M. Holm, and S. Laufer, "Three-component combinatorial synthesis of novel dihydropyrano[2,3-c] pyrazoles," Journal of Combinatorial Chemistry, vol. 10, no. 3, pp. 364-367, 2008.

[16] S. Muramulla and C.-G. Zhao, "A new catalytic mode of the modularly designed organocatalysts (MDOs): enantioselective synthesis of dihydropyrano[2,3-c]pyrazoles," Tetrahedron Letters, vol. 52, no. 30, pp. 3905-3908, 2011.

[17] S. Gogoi and C.-G. Zhao, "Organocatalyzed enantioselective synthesis of 6-amino-5-cyanodihydropyrano [2,3-c]pyrazoles," Tetrahedron Letters, vol. 50, no. 19, pp. 2252-2255, 2009.

[18] H. Mecadon, M. R. Rohman, I. Kharbangar et al., "L-Proline as an efficicent catalyst for the multi-component synthesis of 6-amino-4-alkyl/aryl-3-methyl-2,4-dihydropyrano[2,3c] pyrazole-5-carbonitriles in water," Tetrahedron Letters, vol. 52, no. 25, pp. 3228-3231, 2011.

[19] H. Mecadon, M. R. Rohman, M. Rajbangshi, and B. Myrboh, “ $\gamma$ Alumina as a recyclable catalyst for the four-component synthesis of 6-amino-4-alkyl/aryl-3-methyl-2,4-dihydropyrano[2,3c]pyrazole-5- carbonitriles in aqueous medium," Tetrahedron Letters, vol. 52, no. 19, pp. 2523-2525, 2011.

[20] Y. Zou, H. Wu, Y. Hu et al., "A novel and environment-friendly method for preparing dihydropyrano[2,3-c] pyrazoles in water under ultrasound irradiation," Ultrasonics Sonochemistry, vol. 18, no. 3, pp. 708-712, 2011.

[21] A. S. Nagarajan and B. S. R. Reddy, "Synthesis of substituted pyranopyrazoles under neat conditions via a multicomponent reaction," Synlett, no. 12, pp. 2002-2004, 2009.

[22] M. Bihani, P. P. Bora, G. Bez, and H. Askari, "Mechanochemistry (grinding): an efficient route to synthesize of 6-amino-4 alkyl/aryl-3-methyl-2, 4-dihydropyrano[2, 3c]pyrazole-carbonitrile," Oraganic Chemistry: An Indian Journal, vol. 8, no. 7, pp. 245-247, 2012.

[23] S. Narayan, J. Muldoon, M. G. Finn, V. V. Fokin, H. C. Kolb, and K. B. Sharpless, "On water': unique reactivity of organic compounds in aqueous suspension," Angewandte Chemie, International Edition, vol. 44, no. 21, pp. 3275-3279, 2005.

[24] S. Narayan and W. M. Lindström, Organic Reactions in Water: Principles, Strategies and Applications, Blackwell Publishing, Oxford, UK, 1st edition, 2007.

[25] A. Chanda and V. V. Fokin, "Organic synthesis 'on water," Chemical Reviews, vol. 109, no. 2, pp. 725-748, 2009. 
[26] C.-J. Li, "Organic reactions in aqueous media with a focus on carbon-carbon bond formations: a decade update," Chemical Reviews, vol. 105, no. 8, pp. 3095-3165, 2005.

[27] J. E. Klijn and J. B. F. N. Engberts, "Organic chemistry: fast reactions 'on water,' Nature, vol. 435, no. 7043, pp. 746-747, 2005.

[28] Y. Hayashi, "In water or in the presence of water?" Angewandte Chemie, International Edition, vol. 45, no. 48, pp. 8103-8104, 2006.

[29] R. N. Butler and A. G. Coyne, "Water: nature's reaction enforcer-comparative effects for organic synthesis "in-water" and 'on-water"' Chemical Reviews, vol. 110, no. 10, pp. 6302-6337, 2010.

[30] C.-J. Li and T. H. Chan, Comprehensive Organic Reactions in Aqueous Media, John Weily \& Sons, New York, NY, USA, 2007.

[31] C.-J. Li and T. H. Chan, "Organic syntheses using indiummediated and catalyzed reactions in aqueousmedia," Tetrahedron, vol. 55, no. 37, pp. 11149-11176, 1999.

[32] C. Pétrier and J. L. Luche, "Allylzinc reagent additions in aqueous media," Journal of Organic Chemistry, vol. 50, no. 6, pp. 910-912, 1985.

[33] A. Sato, H. Ito, and T. Taguchi, "Reaction of $\gamma, \gamma$-dialkoxyallylic zirconium species with aldehyde as protected acryloyl anion," Journal of Organic Chemistry, vol. 65, no. 3, pp. 918-921, 2000.

[34] T. H. Chan and Y. Yang, "Indium-mediated organometallic reactions in aqueous media: the nature of the allylindium intermediate," Journal of the American Chemical Society, vol. 121, no. 13, pp. 3228-3229, 1999.

[35] Z. Wang, S. Yuan, and C.-J. Li, "Gallium-mediated allylation of carbonyl compounds in water," Tetrahedron Letters, vol. 43, no. 29, pp. 5097-5099, 2002.

[36] T. C. Chan, C. P. Lau, and T. H. Chan, "Iron-mediated allylation of aryl aldehydes in aqueous media," Tetrahedron Letters, vol. 45, no. 21, pp. 4189-4191, 2004.

[37] K. T. Tan, S. S. Cheng, H. S. Cheng, and T. P. Loh, "Development of a highly $\alpha$-regioselective metal-mediated allylation reaction in aqueous media: new mechanistic proposal for the origin of $\alpha$ homoallylic alcohols," Journal of the American Chemical Society, vol. 125, no. 10, pp. 2958-2963, 2003.

[38] Z. Wang, Z. Zha, and C. Zhou, "Application of tin and nanometer tin in allylation of carbonyl compounds in tap water," Organic Letters, vol. 4, no. 10, pp. 1683-1685, 2002.

[39] S. Otto, G. Boccaleti, and J. B. F. N. Engberts, "A chiral lewisacid-catalyzed Diels-Alder reaction. Water-enhanced enantioselectivity," Journal of the American Chemical Society, vol. 120, pp. 4238-4239, 1998.

[40] S. Kobayashi and K. Manabe, "Development of novel Lewis acid catalysts for selective organic reactions in aqueous media," Accounts of Chemical Research, vol. 35, no. 4, pp. 209-217, 2002.

[41] U. M. Lindström, "Stereoselective organic reactions in water," Chemical Reviews, vol. 102, no. 8, pp. 2751-2772, 2002.

[42] C. Pan and Z.Y. Wang, "Catalytic asymmetric formation of carbon-carbon bond in the presence of water," Coordination Chemistry Reviews, vol. 252, no. 5-7, pp. 736-750, 2008.

[43] Y. Marcus, "Effect of ions on the structure of water: structure making and breaking," Chemical Reviews, vol. 109, no. 3, pp. 1346-1370, 2009.

[44] C.-J. Li, "Organic reactions in aqueous media-with a focus on carbon-carbon bond formation," Chemical Reviews, vol. 93, no. 6, pp. 2023-2035, 1993.
[45] NIST Chemistry WebBook, P. J. Linstrom, and W. G. Mallard, NIST Standard Reference Database Number 69, March , National Institute of Standards and Technology, Gaithersburg MD, 20899, 2003, http://webbook.nist.gov .

[46] R. Breslow, "Hydrophobic effects on simple organic reactions in water," Accounts of Chemical Research, vol. 24, no. 6, pp. 159-164, 1991.

[47] N. Akiya and P. E. Savage, "Roles of water for chemical reactions in high-temperature water," Chemical Reviews, vol. 102, no. 8, pp. 2725-2750, 2002. 

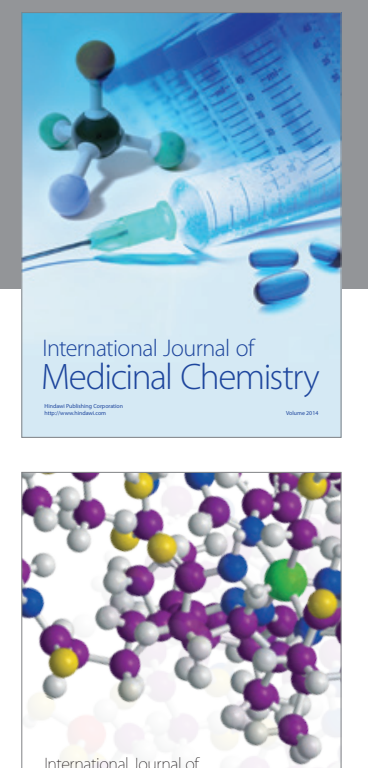

\section{Carbohydrate} Chemistry

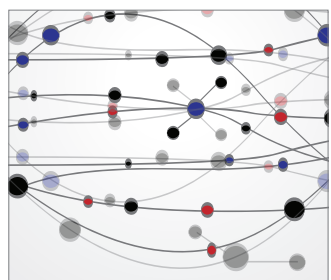

The Scientific World Journal
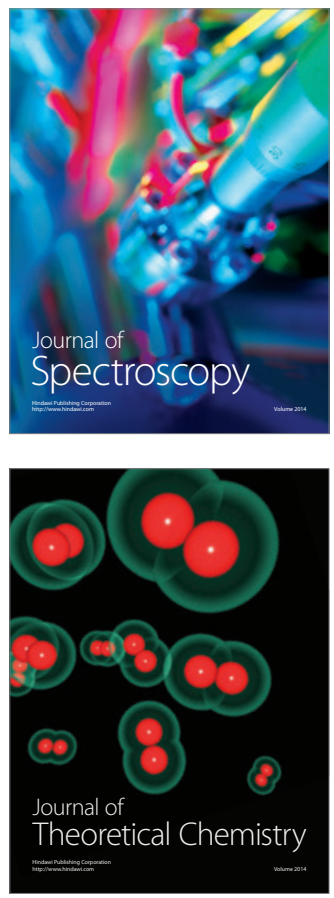
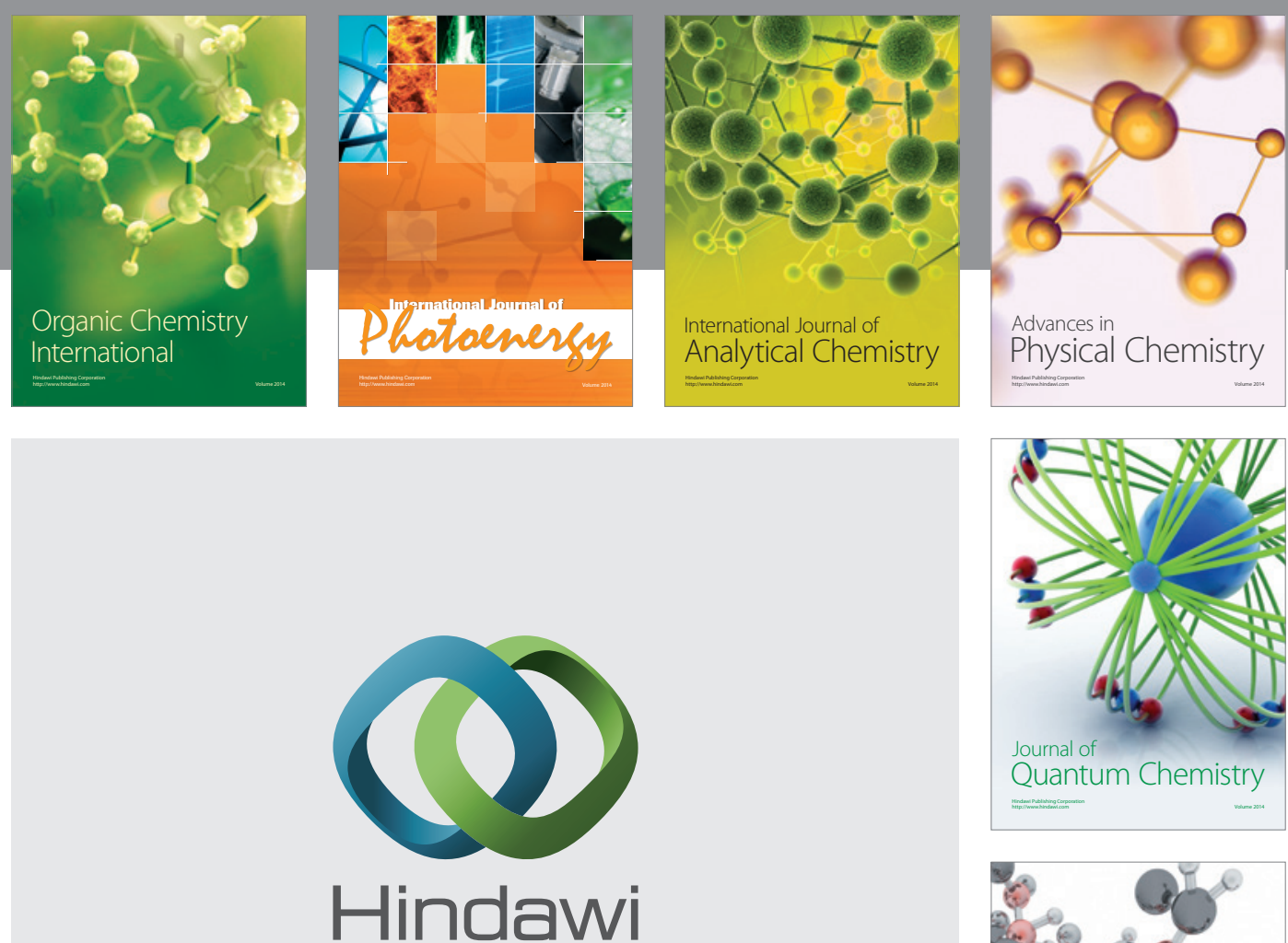

Submit your manuscripts at

http://www.hindawi.com

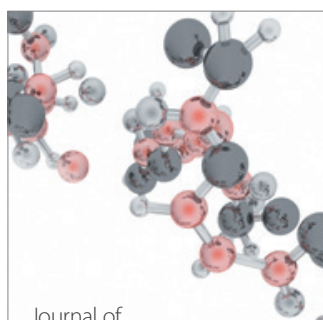

Analytical Methods

in Chemistry

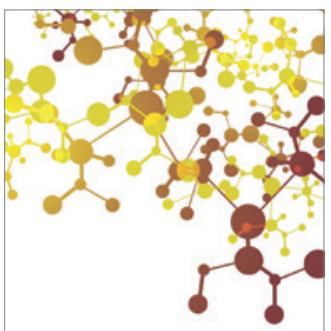

Journal of

Applied Chemistry

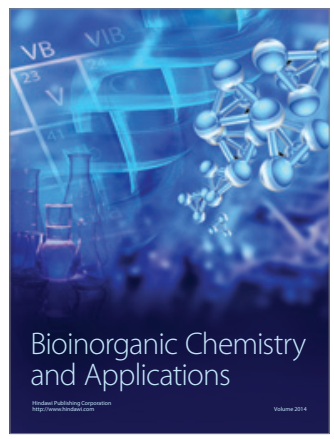

Inorganic Chemistry
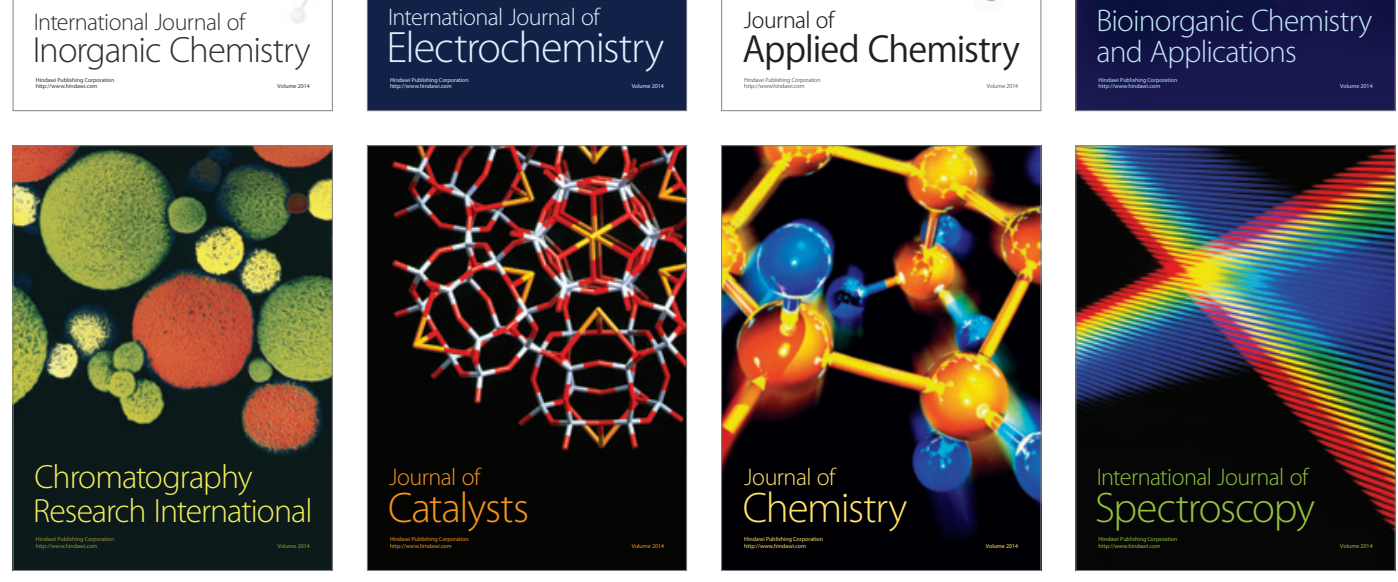